\title{
ESTÉTICA DA LIBERDADE EM IONESCO
}

\author{
João Ricardo Moderno ${ }^{1}$
}

RESUMO: Neste artigo, defendemos em linhas gerais o valor universal da defesa da liberdade e do humanismo presentes nos diversos textos e entrevistas de Ionesco, enfatizando que a estética de seu "teatro do absurdo" procura antepor às forças centrífugas das manifestações políticas totalitárias o emprego artístico da imaginação criadora.

PALAVRAS-CHAVE: Ionesco; Liberdade; Imaginação Criadora.

\begin{abstract}
In this paper, we defend in general terms the universal value of the defense of freedom and humanism present in various teoretical texts and interviews of Ionesco, emphasizing that the aesthetics of his "Theater of the Absurd" aims to put in front of the centrifugal forces of totalitarian political demonstrations the artistic use of creative imagination.
\end{abstract}

KEYWORDS: Ionesco; Freedom; Creative Imagination. 

Aristóteles dizia que a filosofia nasce do assombro do viver. Viver do assombro é tarefa do filosófo. Nesse sentido, Eugène Ionesco foi um filósofo no mais amplo sentido. Um filosófo do assombro da criação, da imaginação criadora. Segundo ele, "o erro de André Breton talvez tenha sido de se levar muito a sério demais. É preciso se levar um pouco a sério, senão é a inconsistência. Mas se se leva a sério em excesso, não há mais liberdade, é a prisão, a asfixia. Não se é verdadeiramente mais "livre em seus movimentos". Não se mexe mais, se é tomado, colado às coisas, não se tem mais a distância necessária para ver. É preciso ser sério pela metade" (IONESCO, 2007) Ionesco, assim, criou uma das mais sérias obras do teatro contemporâneo. Ao invés de ficar colado às coisas, transformou-as em coisas artísticas. Teatro é uma reinvenção das coisas do mundo empírico em uma expressão que as apresenta como coisas do mundo artístico, ressemantizandoas, e tornando-as paradoxal, simultânea e contraditoriamente pertencentes ao mundo real e ao heteromundo da imaginação criadora. Em 1978, Ionesco concede entrevista à TV FR3, publicada na Revista Tel Quel, que "Eu não sei quem sou. Eu não sei o que faço aqui. Eu não sei nem de onde vim, nem para onde eu vou" (IONESCO, 1979, p.7). Esse o grande Ionesco. Um dos maiores gênios do teatro, da arte, da cultura e do pensamento crítico, membro da Academia Francesa, não há ninguém que possa querer ensinar a Ionesco o que é cultura e o que é criação, e muito menos os que nunca criaram nada.

$\mathrm{O}$ teatro não é filosofia. Afirma Ionesco que

o teatro não deve ser filosófico, mas como toda poesia é filosofia, o teatro o é certamente de uma maneira indireta. Não é filosófico tomar consciência de estar face ao mundo 
e de se perguntar 'o que é que é isso'? Tudo é filosofia em um certo sentido, ou tudo procede da filosofia. O teatro procede também dessa interrogação. Ele deve mesmo dela proceder sob pena de ser insuficiente, insignificante. Somente, ainda uma vez, digamos filosofia e não doutrina ideológica, filosofia e não ideologia. A arte é filosófica na medida em que a filosofia é exploração, problema, questão, atitude. Eu chamo ideologia um sistema fechado dando explicações clicheristas (BONNEFOY, 1966, p.145).

Ionesco, por entre seus diversos textos teóricos, entrevistas teóricas, condena os totalitarismos comunista e nazista, além do incipiente totalitarismo islâmico dos anos 1960 e 1970, pela total catástrofe humana, econômica, política, científica e artística. Ionesco jamais transigiu com a destruição da liberdade. Crítico feroz do aborto, da eutanásia, do racismo e de todas as formas de barbárie e de tirania, Ionesco cita o caso de um professor aleijado de uma universidade alemã (IONESCO, 1977, p.18): "Nascido durante o nazismo, sua mãe o escondeu porque os médicos, geneticistas, biólogos nazistas, assim como os sociólogos, não aceitavam que ele vivesse. Toda vida deve ser salva, toda vida é fonte de sofrimento, mas também de alegria e de contemplação. Mas tudo isso, eutanásia exercida sobre os velhos, enfermos ou aleijados, o aborto, tudo isso faz parte de um conjunto: desprezo da vida, desprezo do espírito, desprezo do homem, desprezo da metafísica, desprezo da vida pessoal; a sociedade antes de tudo, a saúde da nação, da raça, tudo isso faz parte da 'moral' totalitária. [...] Que pena, o humanismo se vai em pedaços", lamenta o dramaturgo. Segundo Ionesco, o humanismo tornou-se tão ridículo quanto na época do nazismo, destruidor do humanismo. Diz ele: "Acho que Hitler ganhou. Eu creio que a imensa crueldade nazista nada mais era que o signo precursor do ódio e 
da raiva de destruição que ganha toda a humanidade, começando hoje pelo burguês de esquerda, mas que são bem os filhos dos burgueses nazistas e fascistas dos anos 30 a 40", protesta Ionesco com tristeza (Idem, ibidem, p. 44). Aqui ele adverte o início de uma nova regressão à barbárie, como se o Ocidente não tivesse aprendido a lição da catástrofe. Vale lembrar que Ionesco sempre foi um defensor apaixonado do Estado de Israel, um amoroso dos judeus sempre perseguidos e ameaçados de extermínio e genocídio. Palavra de "cristão, mal cristão, mas cristão", como disse.

Condenando a posição da Igreja Católica em ser refém voluntária da História, confundindo-se com a História, o que acabou levando-a a ser aceita e infiltrada pelo marxismo, pelo comunismo, Ionesco, o mal cristão, se dá ao luxo de ensinar cristianismo ao Padre Lendger, que o entrevistara. Confessa ao padre que a Igreja abandonou a linguagem sagrada, adotando a linguagem do século, mundana. A Igreja Católica teria renunciado, capitulado, perante a História. Ao final da entrevista de 1975, o Padre Lendger pergunta a Ionesco o que ele teria a dizer a um padre como ele. A resposta é fantástica: "Eu diria a ele: por que veio em minha casa em trajes civis? [...] Coloque uma batina. $\mathrm{O}$ que é essa gravata? $\mathrm{O}$ senhor de gravata fica como todo mundo. Eu preciso de ver alguém que está fora do mundo, no mundo mas ao mesmo tempo fora do mundo" (Idem, ibidem, p.248). A defesa do sagrado no pensamento de Ionesco é de uma veracidade e uma autenticidade impressionantes.

O pensamento de Ionesco possui variações centrípetas a partir da liberdade, conduzindo ao pensamento filosófico estético, político, religioso, ético, econômico, social, militar, etc. Todas as forças centrífugas dos totalitarismos são abominadas e duramente criticadas. $\mathrm{O}$ eu criador de Ionesco é centro das suas reflexões, quando ele procura dramática, 
exasperada e obsessivamente inventar um novo mundo a partir do existente e fundado na sua mais íntima e profunda imaginação criadora. Até mesmo as ironias da falsa e leviana "crítica literária", não certamente a alta crítica, que ele estimava vivamente, mas a crítica superficial voltada para elementos para lá de secundários, como se toda a obra de Ionesco fosse somente redação de confissões pessoais. Assim, diz ele,

todo mundo é somente porteiro, pessoas mundanas, isto é, porteiros a um grau superior [...] Toda história literária tal como se pratica é uma história de porteiros. O que diz um camarada, os jornalistas, os leitores, não o compreendem como um artista, como um sacerdote, como um médico, como um psicólogo o entendem. Eles não vêem o que significam essas confissões, o que significa a verdade mais profunda, a mais universal, de uma confissão particular. $O$ que os interessa não é a verdade universal, mas a confissão pessoal, isto é, o buraco da fechadura. O que interessa às pessoas não é o que pode aí ter de universal ou de geral na obra particular de um escritor, mas de conhecer suas historinhas. Ainda de novo, isso é o que não é a obra. As origens são interessantes em estudar, a obra o é muito mais. A obra é mais que suas causas, ultrapassa suas causas (BONNEFOY, 1966, p.67).

Com efeito, Ionesco consagra-se como um dos maiores teóricos da estética contemporânea, seja utilizando uma linguagem mais formal em artigos densos, seja mais informal, como nos artigos para jornais e revistas, nas entrevistas, notas, panfletos, polêmicas e memórias artísticas.

Ao lado de Samuel Beckett, Ionesco forma a mais importante dupla do chamado "teatro do absurdo". Ionesco por inúmeras 
vezes tece elogios críticos a Beckett, afirmando, por exemplo, e contrariamente a Sartre, por quem nutria desprezo pela filosofia, pelo teatro e pelas posições políticas, que

Beckett não corre atrás da História, ele flutua. Ele exprime verdades, angústias e obsessões fundamentais que se encontram expressas todos os três ou quatro séculos. Beckett só é exclusivamente em seus livros ou em seu teatro. Um dia eu disse que ele era contemporâneo do Rei Salomão ou de Jó. É o autor de língua francesa de hoje que me parece o mais importante. Ele, Beckett, resiste à corrente da história (IONESCO, 1977, p.102).

A imaginação criadora em Beckett e Ionesco são assessoradas pela angústia vital, pela obsessão criadora, pela revolta da desrazão em meio a um mundo profundamente irracional. Para Ionesco, "a obra de Beckett é um apelo permanente a Deus, é exatamente um S.O.S." (Idem, ibidem, p.243).

Liberal em todos sentidos, Ionesco escreveu belas páginas sobre o Estado opressor, repressor e tirânico, inimigo da arte porque inimigo da liberdade. Assim, diz ele que não cabe ao Estado se substituir aos artistas e jornalistas.

A liberdade, afirma Ionesco, pela qual se tinha pretendido combater, foi abolida. A fraternidade ou o amor tornaram-se coisas desprezíveis e ridículas, ou 'sentimentalismo burguês'. Em nome de uma mítica revolução, pretensamente proletária, somente os dirigentes têm o poder e a palavra. 'Não há mais críticas a fazer em nosso país, me dizia certa vez em uma reunião internacional, o Ministro da Cultura da União Soviética. Marx chegou, a revolução foi feita, os que são contra nós são contra a sociedade'(Idem, ibidem, p.135). 
Em Ionesco, os inimigos da liberdade de expressão artística são os inimigos da liberdade econômica, política, jornalística, científica, filosófica, religiosa e cultural em geral. O Estado não tem alma, escreveu Edith Stein, e exatamente por isso Ionesco afirma que cultura não é um assunto do Estado, mas dos artistas, dos criadores. $\mathrm{O}$ totalitarismo quer fazer do Estado uma obra de arte viva, um ser, ontologicamente qualificado, e para isso é preciso praticar o genocídio, ou mais recentemente, assassinatos seletivos, direcionados simbolicamente. $\mathrm{O}$ totalitarismo quer reinventar a natureza humana, mas preservando a dominação feroz dos líderes sobre as massas oprimidas.

A dominação e o autoritarismo sobre os artistas pela Unesco são examinados criticamente por Ionesco ao citar que

Simone Weil pensava que a cultura é um instrumento manipulado por professores para fabricar professores que por sua vez fabricarão professores'. A cultura parece em nossos dias ser um instrumento manipulado por funcionários públicos para fabricar funcionários públicos que fabricarão funcionários públicos. Isto significa, na realidade, assim como pensava verdadeiramente Simone Weil, o contrário da cultura. [...] Ninguém parecia querer compreender que a verdadeira cultura viva é criação, ruptura, mudança, evolução e mesmo revolução. Do Ocidente ao Oriente, do sul ao norte, oficialmente a cultura parece ser de todo modo o pão cotidiano dos burocratas, o monopólio e o cassetete dos políticos autoritários. [...] E quem são as pessoas levadas a pensar as políticas culturais e em aplicá-las? Os políticos, claro, e os burocratas. Eles consideram os artistas como menores incapazes, e que de qualquer jeito eles devem ser pelo menos vigiados (Idem, ibidem, p.141). 
Desde Platão, que expulsara os poetas da República, até hoje, os artistas são um estorvo para o Estado que não sabe exatamente como lidar com eles. Principalmente, para o Estado totalitário, por muitos especialistas um platonismo redivivo.

Defensor da vanguarda artística como liberdade, Ionesco descreve um encontro da Unesco sobre teatro em 1958 com a participação do bloco soviético, e percebendo a semelhança autoritária entre os representantes oficiais ocidentais e orientais. Segundo ele,

os russos que, até aqui haviam deixado falar os satélites, foram convidados pela presidente a responder aos últimos. Depois disso, a sessão foi interrompida. Os soviéticos só falavam besteiras. Assim, eles declararam que em seu país o teatro não estava em crise pois havia não sei quantas centenas de teatros na Rússia, outras centenas ou milhares de refeitórios para os atores, centenas e mesmo milhares peças de teatro que eram publicadas ou encenadas cada ano: o que quer dizer que a quantidade tornavase qualidade, dezenas de milhares de abobrinhas se transformavam de repente em obras-primas. Depois eles começaram a me atacar pessoalmente, recusando o debate essencial. Os delegados russos afirmaram que, sem dúvida, eu era um doente, e que eles haviam construído e instalado hospitais psiquiátricos para os escritores antissociais. Os russos, exatamente eles, podiam me curar, e podiam curar igualmente todos os autores malsãos, excêntricos, rebeldes. Foi a primeira vez que ouvi falar de hospitais psiquiátricos soviéticos para artistas e intelectuais. Imaginem vocês, isso já existia, mas eu só acreditava pela metade. Eu achava que isso era um modo de dizer, uma brincadeira. Desde então nós sabemos que isso existe. [...] $\mathrm{O}$ mais desagradável, é que o diretor geral da Unesco parecia querer fazer a balança tender para o lado soviético. Eu havia 
constatado na Unesco uma certa tentativa de infiltração de comunistas e simpatizantes (Idem, ibidem, p.147-150).

Esse depoimento estarrecedor de Ionesco revela fidedignamente o ambiente político da guerra fria. A barbárie totalitária na sua face mais brutal e cruel com os artistas, remetendo ao conceito ionesquiano de Estados concentracionários, isto é, que são campos de concentração, como foram a União Soviética, a China, Cambodja, Albânia e diversos outros, e hoje Cuba, Coréia do Norte, entre outros assemelhados. A usurpação do Estado e organismos internacionais dos direitos dos artistas é uma manifestação contrária à verdadeira cultura. Os tiranos tornam-se críticos de arte e artistas simultaneamente, ditando o que tem valor ou não, o que é decadente, degradante e indefensável. Com efeito, para Ionesco, "toda a cultura foi feita por inimigos da cultura. Toda a história é um combate contra a história, e isso é seu paradoxo e sua verdade" (Idem, ibidem, p.159). Ionesco considera o liberalismo a mais elevada forma de organização política, econômica, cultural e social, pois permite a crítica e a oposição. Segundo ele, somente o Estado totalitário impõe valores culturais, enquanto o Estado liberal aceita tudo. Nada mais reacionário e atrasado que os totalitarismos soviético, cubano, chinês, nazista, islâmico e outros, conforme Ionesco. E é exatamente uma "burguesia" assassina que forma a classe dirigente dos Estados totalitários.

Se filosofia não é ideologia, arte e literatura muito menos. Indagado sobre a função da literatura, Ionesco esclarece o seguinte:

Eu creio que não há nada mais interessante que inventar histórias, e contá-las. Não há coisa ao mesmo tempo mais prazerosa e mais importante na vida. Contudo, se insere na literatura todo tipo de coisas, a preocupação ideológica, a propaganda, etc. É o desinteresse da literatura que é 
interessante. [...] Os autores escritores fazem propaganda, fazem ideologia, mas os grandes autores são aqueles que, apesar deles, fizeram outra coisa que propaganda, e outra coisa que ideologia (Idem, 1979, p.9-10).

Ao tornarem a literatura uma atividade heterotélica, os autores se desviam da máxima de Kant segundo a qual a arte é uma atividade sem fim determinado. Regra geral, os artistas engajados ideologicamente são presas fáceis da instrumentalização da obra de arte como propaganda político-ideológica. A arte perde $\mathrm{o}$ seu caráter enigmático, como já denunciara Theodor Adorno.

Desde Kant a arte é definida como um prazer desinteressado, e uma finalidade sem fim determinado, como bem assinalou o filósofo francês Victor Basch, judeu da Resistência, nome de sala no Departamento de Filosofia da Université de Paris I - Panthéon - Sorbonne, e nome de uma agradável praça em Paris. Desse modo, Ionesco permanece convicto do caráter desinteressado da arte, e resiste criticamente ao assédio dos políticos: "E eu me dou conta que, por exemplo, eu fui muito ingênuo em lutar tenazmente em querer provar que há atividades desinteressadas, enquanto que sabe disso todo mundo que já jogou futebol, cartas, xadrez, jogo do ganso, etc. Somente os políticos não querem que a atividade teatral seja desinteressada e gratuita, eles detestam que ela seja livre, e que ela lhes escape" (Idem, 1966, p.11). A autonomia da obra de arte explicitamente nomeada desde Alexander G. Baumgarten, pai da estética como tal no século XVIII alemão, passando por Kant, Schiller, Diderot, e os românticos alemães até Theodor Adorno no 
século XX, é uma reivindicação histórica dos defensores da liberdade de criação e expressão. A identidade entre a arte e o jogo é uma das mais intrigantes manifestações do enigma da criação. A não identidade entre as duas atividades é uma sutil diferença no campo da cultura.

O enigma da obra de arte é a conditio sine qua non de uma criação artística livre, fora isso é propaganda, ou mais ou menos propaganda. Vale dizer que essa é uma tendência ou uma invariante do pensamento totalitário, pois o pensamento liberal na arte contemporânea criou todas variações da Arte Moderna e pós-moderna, termo este cunhado pelo crítico brasileiro Mário Pedrosa em 1951 aproximadamente, para designar avanços na Arte Moderna, inclusive por artistas brasileiros, como Abraham Palatnik, de quem fui amigo. Aliás, Mario Pedrosa, da velha esquerda, também meu amigo ao final da vida, me confessava em entrevista - a última - a incompatibilidade do marxismo com a arte livre, de vanguarda. Diga-se de passagem, que quase toda a grande crítica de arte brasileira do século XX foi da esquerda marxista, e jamais souberam como resolver a conciliação entre a liberdade da arte que defendiam com ardor e paixão, e o sistema totalitário comunista que defendiam com o mesmo ardor e paixão, e que negava a liberdade da arte. Pode-se dizer o mesmo de diversos artistas. E até hoje.

Com efeito, para Ionesco arte é enigma, como em Theodor Adorno. Embora ele mesmo ache que Beckett o superou no enigma da obra de arte, e que ele deveria ter permanecido mais dentro do incompreensível, do inextricável. Isso é a metafísica da arte. A física da arte é o veículo empírico que precisa conduzir o receptor 
da obra para a metafísica da arte, a única que faz sentido ao romper com o sentido prosaico do mundo.

Desapontado com Sartre, Foucault e vários outros intelectuais franceses que sempre silenciaram sobre o genocídio praticado pelos comunistas e totalitaristas em geral - vale lembrar que Michel Foucault apoiou desde sempre o totalitarismo islâmico a partir de Paris, onde frequentava a casa do grande amigo Aiatolá Khomeini, liderando um curso sobre Heidegger, e tendo como ouvinte o também grande antissemita Mahmoud Ahmadinejad, e em louvor à Revolução Islâmica até a morte, inclusive escrevendo como correspondente em Teerã para o jornal Corriere della Sera, apoiando as atrocidades do regime bárbaro -, Ionesco desabafou em 1978:

Nós não podemos confiar na intellighèntzia. A intellighèntzia é muito sensível aos retrocessos irracionais e à força politica. Essa é a razão pela qual é muito difícil de confiar nos intelectuais, naqueles chamados "intelectuais", porque longe de serem mestres do pensamento, eles são intermediários dos escritórios de propaganda, sobretudo dos governos comunistas, eles são os intermediários entre o público e as indústrias de propaganda (Idem, 1979, p.28).

Com efeito, Michel Foucault começa a desabar com as publicações críticas sobre a sua obra jornalística, inclusive por parte de filósofos iranianos independentes e, claro, morando no exterior.

Ionesco sempre discutiu criticamente as relações entre a cultura e a política, nas quais ele desvela como a primeira é sempre perdedora. Desta feita, 
a cultura é indissociável da política. A cultura e a política são a nossa vida. De fato, as artes, a filosofia e a metafísica, a religião ou outras formas de vida espiritual e as ciências constituem a cultura. [...] Mas se a política é a organização de toda sociedade possível, ela tornou-se anarquicamente organização pela organização, que dizer, de fato desorganização do complexo cultural em detrimento da metafísica, diretora da arte, da espiritualidade e mesmo da ciência. Desenvolvendo-se, portanto, pisando nas outras atividades humanas, ela tornou a humanidade louca. A política não é mais que um combate maluco pelo poder, mobilizando e monopolizando todas as energias do homem moderno. Na realidade, não há mais ideologia, nem filosofia, nem arte, nem mesmo a ciência nos países totalitários escapa da política. O saber e a criação estão subordinados à política (Idem, 1979, p.49).

Para Ionesco a política é a morte, pois ela matou a filosofia da qual pretendia ser herdeira, e com isso sacrificou todas as relações verdadeiras que poderiam, e deveriam, haver entre as ideias filosóficas e a sua aplicabilidade prática nas sociedades. Com isso, o divórcio tornou a política uma atividade autotélica, voltada para os seus próprios fins particulares, deixando de ser um meio para o desenvolvimento. A política termina por ser um fim em si mesma. Inimiga da cultura, a política vê-se a cada dia inimiga de mais e mais atividades humanas, como as empresariais e econômicas, científicas, filosóficas, esportivas, religiosas e outras, em maior ou menor grau. Repensar o sentido da política, eis uma urgente tarefa crítica. Até para que ela mesma não morra, após ter matado todas as outras atividades. Salvar a cultura é uma tarefa a priori, dado que

a cultura é a expressão de nossa continuidade e nossa identidade multissecular através do tempo, do espaço, 
e das sociedades universais, e eu diria que a forma mais alta da preocupação humana é a arte, que parte do social rumo a um ponto de encontro extrassocial e suprassocial que reúne todos os homens: a diversidade indispensável à unidade de nosso espírito, à solidariedade além do tempo e do espaço. [...] A cultura é o desabrochar do indivíduo. [...] A personalidade individual, em seu desenvolvimento pleno, pode parecer ser contra os outros, mas de fato ela é a favor dos outros. É o indivíduo que é portador de valores, é o criador original que permite a renovação da sociedade nessa síntese de coletivo e individual (Idem, 1979, p.52).

A alma mesma da cultura é a obra de arte. E o que é arte? Entre inúmeras definições do que é ou não é arte, Ionesco explicita uma delas:

Nenhuma definição da arte é satisfatória. Os defeitos de uma obra reaparecem quando a análise leva em conta uma heterogeneidade que dissolve a obra, quando ela contém contradições que se neutralizam ao invés de se oporem de uma maneira criativa, viva. Uma obra é ruim quando ela não é ela mesma, quando ela não permite a constatação da existência de alguma coisa como um ser único [...] Portanto, a obra é organizada, eu quero dizer que ela é um organismo. É nisso que uma obra é verdadeira, e a arte confunde com a verdade. Essa verdade, evidentemente, é subjetiva, e é essa verdade subjetiva que é a única verdade do artista. Uma subjetividade tão total, tão profunda, que ela termina por alcançar a objetividade: o artista deve ser objetivo ou verdadeiro na sua subjetividade. A obra é a expressão de uma visão, esta visão toma corpo, isto é, é organizada, ainda uma vez ela é um organismo vivo contendo nela mesma todos os antagonismos que devem constituí-la mas não a destruir. Mais as oposições, as linhas de força e as paixões 
são complexas e numerosas, mais a obra é importante, e pois que a obra é como um organismo vivo, como um ser, é nisso que ela é ao mesmo tempo invenção e descoberta, imaginária e real, útil e inútil, necessária e supérflua, objetiva e subjetiva, literatura e verdade. Ela procede de um jogo que não é uma mentira. Claro, pode-se rejeitar essa obra, pode-se julgá-la nefasta, como se pode condenar e matar alguém. [...] A obra é um ser autônomo. Criticar é discernir. Discernir, ou ver, é distinguir (Idem, 1966, p.32-33).

Com efeito, a obra de arte conclusa e exitosa é a que explora criticamente todas as contradições que surgem ao longo e através do processo objetivo e concreto da imaginação criadora. Quanto mais contraditória a obra de arte mais verdadeira ela se forma. Pretender eliminar as contradições para torná-la mais coerente é destruir a alma mesma da arte. A rede de contradições subjetivas ao ascender ao concreto da realização formal torna-se mediatamente objetiva, como que por camadas sucessivas em direção à objetividade singular. As contradições objetivas da subjetividade da imaginação criadora plasmam a objetividade formal. Nós podemos falar em verdade da arte exatamente nesse sentido, sem prejuízo de podermos falar de verdade artística em outros momentos da realização concreta da formatividade estética. Assim,

uma obra deve ser nova, ela deve ainda ser verdadeira. Esta verdade é muito simplesmente a expressão de uma sinceridade profunda do artista. [...] partindo de sua subjetividade, exprimindo sua subjetividade, o criador objetiva-se. Saída de si, exteriorizada, a obra adquire uma existência em si. [...] Diz-se que o autor escrevia uma peça, que os atores encenavam uma outra, e que os espectadores viam um terceira. A situação é ainda bem mais complexa. A verdade de uma obra é mais dividida, 
e essas verdades divididas se chocam, se opõem umas às outras, se negam a tal ponto que parece sobrar da obra somente um pretexto com múltiplas interpretações contraditórias, a obra parecendo nada mais que o lugar de encontro das interpretações da qual a obra é como que um pretexto ultrapassado (Idem, ibidem, p. 37).

Vale lembrar que Ionesco nunca defendeu o sincerismo, que é o sentimentalismo exacerbado, ao contrário, ele usa o kitsch de modo acidamente crítico, como que em modo especular. Bons sentimentos são somente bons sentimentos, e não boa arte. Parafraseando João Cabral de Melo Neto, que afirmou que não fazia poesia com emoção, mas para gerar emoção, a arte precisa gerar bons sentimentos no público. Na estética de Ionesco, as verdades divididas são as contradições artísticas da veracidade dos impulsos da imaginação criadora, a única faculdade humana que habilita a pessoa humana individual a alcançar a obra de arte, que como o próprio nome define, é forma, construção, resultado físico.

Retomando, Ionesco esclarece:

Nós dissemos que o criador autêntico é de uma sinceridade absoluta. O que ele diz é verdade, mas qual é esta verdade, qual é esta sinceridade? As histórias que o autor nos conta são inventadas, portanto elas não são verdadeiras. Ela são inventadas, e é justamente por isso que o autor não mente. Com efeito, inventar é criar, é se descobrir. Já que a obra criada é inventada ou imaginada, ela é um ser vivo, como dissemos. Um ser vivo e real. Uma obra é de uma realidade indiscutível. Mentir é dissimular, ou bem é tentar substituir uma realidade por uma outra realidade. É trapacear, é negar ou afirmar coisas com um objetivo, mesquinho ou 
moralmente generoso, de impostura ou de propaganda. [...] $\mathrm{O}$ autor não substitui uma coisa por uma outra, como faz o mentiroso; ele faz uma coisa que é esta coisa. É por isso que a verdade toma suas fontes no imaginário. [...] Nascida dele, ela lhe escapa. De uma certa maneira, um autor de tese é um falsário. Ele conduz seus personagens rumo a um objetivo determinado, ele lhe impõe uma direção, ele sabe antecipadamente o que eles devem ser, ele aliena a liberdade de seus próprios personagens e de sua própria criação. Sua arte não é uma exploração pois ele é vassalo de um campo já explorado, suas criaturas nada mais são que marionetes, não haverá mais revelações no que ele faz, mais simplesmente ilustração, exemplificação. Tudo é dado desde o começo. $\mathrm{O}$ autor de tese não pode mais ser um autor de boa fé, ele não é mais sincero. Ao mesmo tempo, claro, nem sua obra, nem seus personagens poderão mais nos surpreender. Nenhuma tese é absoluta e objetivamente verdadeira. $\mathrm{O}$ autor de tese dá a esta a prioridade sobre toda outra verdade possível (Idem, ibidem, p. 41).

Voltamos, assim, a reforçar o caráter desinteressado da arte, muito enfatizado por Olivier Revault d'Allonnes em seu livro sobre Beethoven, e o desinteresse está diretamente ligado ao conceito kantiano de finalidade sem fim determinado, como completou Victor Basch. Determinar um objetivo desde o ponto de partida já é corromper o processo de criação como um todo. Trair a verdade da arte, que se revela pouco a pouco pela expressão da imaginação criadora, cuja formatividade toma seu próprio rumo e direção, como que tendo independência e vida própria, deixando o autor. $\mathrm{O}$ autor de tese como artista perverte a ideia mesma de criação, fazendo uso político-partidário, ideológico, propagandístico, e menos arte verdadeira. O termo francês l'auteur à thèse é 
muito bem apropriado, trazendo em si uma crítica aos artistas que transformam a obra de arte em uma oportunidade de quase sempre defender uma tese política, comprometendo e inviabilizando a verdade da criação, que se quer e precisa ser livre. O autor de tese quer demonstrar e defender uma tese, uma verdade produzida artificial e ideologicamente por ele, mas que não nasceu dele através da expressão natural e cultural da imaginação criadora livre secundada pela razão, ao contrário, a razão assume a liderança a serviço da política, secundada pela imaginação criadora. Aliás, que de criadora somente resta o nome.

Assim, em Ionesco a verdade

está em nossos sonhos, na imaginação. Tudo, a cada instante, confirma esta afirmação. A ficção precedeu a ciência. Tudo aquilo que sonhamos, isto é, tudo aquilo que nós desejamos, é verdadeiro. [...] Só o mito é verdadeiro. [...] A realidade não tem que ser realizável: ela nada mais é o que ela é. É o sonhador, ou pensador, ou o sábio, que é revolucionário, é ele que tenta mudar o mundo. [...] Eu creio compreender agora aquilo que me incomodava no teatro, era a presença no palco de personagens em carne e osso. Sua presença material destruía a ficção. Havia lá como dois planos de realidade, a realidade concreta, material, empobrecida, esvaziada, limitada, dessas pessoas vivas, quotidianas, mexendo e falando em cena, e a realidade da imaginação, todas duas face a face, não se unindo, irredutíveis uma à outra: dois universos antagonistas não chegando a se unificar, a se confundir (Idem, ibidem, p. 48-49).

É dessa contradição estética entre a realidade empírica e a realidade artística que Ionesco extrai uma poderosa fonte de criação. O peso enorme da realidade viva dos atores associado às demandas do inconsciente da imaginação criadora produz 
uma contradição estética que, longe de Ionesco denegar, tornar-se motivo de exploração criadora. É da essência mesma do teatro a contradição estética entre a realidade empírica e realidade imaginadora. $\mathrm{O}$ mundo empírico fornece as condições para as contradições com o mundo da imaginação criadora. Em concordância com Vico, Ionesco confirma que a ficção precedeu a ciência, pois a imaginação precede a razão.

Quando o artista se deixa levar pela força da correnteza da realidade empírica, ele é sequestrado pela força da tese, ou força das ideias, que o vincula ao mundo e não à imaginação criadora, $\mathrm{e}$ esta passa a se subordinar àquela. A função da arte não é de rivalizar ou de colaborar com a ciência, a política, a ideologia ou quaisquer formas de repressão ao inconsciente criador, à intuição artística e aos impulsos espontâneos da imaginação criadora. Nesse sentido, Ionesco critica Pirandello, que se vale da ciência da psicologia para construir seus personagens, o que conduz à insuficiência do teatro pirandelliano diante da psicologia, e simultaneamente uma insuficiência diante do próprio teatro. Pirandello poderia ter ido mais longe caso não subordinasse seu teatro à psicologia. Assim,

o valor do teatro de Pirandello não leva em conta a contribuição deste à psicologia, mas à sua qualidade teatral, que está necessariamente alhures: neste autor, não é mais a descoberta dos antagonismos da personalidade que nos interessa, mas o que ele faz disso, dramaticamente. Seu interesse propriamente teatral é extracientífico, ele está além da sua ideologia. Em Pirandello, sobrou apenas sua mecânica teatral, seu jogo: prova ainda que o teatro que só é construído sobre uma ideologia, uma filosofia, e que deve tudo exclusivamente a esta ideologia e a esta filosofia, está construído com areia, cai por terra. É a sua linguagem teatral, seu instinto puramente teatral que faz com que Pirandello ainda esteja vivo hoje (Idem, ibidem, p.56). 
A instrumentalização da arte pela ideologia, seja política ou científica, está no oposto do sentido próprio da criação, que no seu autêntico processo ruma em direção ao desconhecido, isto é, não sabe aonde vai chegar. E se vai chegar. Arte não é ilustração da ciência, tampouco da política. Teatro é a radicalização estética da linguagem do teatro. Ionesco frisa bem que não são os antagonismos psicológicos que garantem o teatro, mas sim as contradições estético-artísticas, nas quais os personagens são parte ativa. A arte não é simples representação do mundo interior e exterior, porém, a reinvenção do mundo. A lógica que rege a ciência e a paixão que dirige a ideologia são insuficientes para a arte, que recorre à imaginação criadora para impedir a mutilação do espírito. E do corpo.

Com efeito,

as peças de tese são grosseiras. O teatro não é a linguagem das ideias. Quando ele quer se fazer o veículo das ideologias, ele só consegue ser o seu vulgarizador. Ele as simplifica perigosamente. Ele as torna primárias, as rebaixa. Ele torna-se 'naïf', mas no mal sentido. Todo teatro de ideologia corre o risco ser exclusivamente teatro de clientelismo político. Qual seria, não a sua utilidade, mas sua função própria, se o teatro fosse condenado a fazer unicamente duplo emprego com a filosofia, ou a teologia, ou a política, ou a pedagogia? Um teatro psicológico é insuficientemente psicológico. Melhor ler um tratado de psicologia. Um teatro ideológico é insuficientemente filosófico. Ao invés de ver uma ilustração dramática de tal ou tal política, eu prefiro ler meu jornal de sempre, ou escutar falar os candidatos do meu partido. Descontentes com a ingenuidade grosseira do teatro, filósofos, literatos, ideólogos, poetas refinados, pessoas inteligentes tentam tornar o teatro inteligente. Eles escrevem com inteligência, com gosto, com talento. Eles colocam nele o que eles pensam, eles exprimem suas 
concepções sobre a vida, sobre o mundo, consideram que a peça de teatro deve ser uma espécie de apresentação de uma tese, da qual surge, no palco, a solução. Eles dão por vezes às sua obras a estrutura de um silogismo do qual as premissas seriam os dois primeiros atos, e o terceiro ato seria a conclusão (Idem, ibidem, p.57-58).

Ionesco reivindica o direito do teatro de ser exclusivamente teatro, o direito à autonomia da criação. $\mathrm{O}$ teatro de vanguarda de Ionesco é uma das mais importantes expressões da liberdade da imaginação criadora da história do teatro. Ainda que não de maneira exaustiva, em linhas muito gerais, portanto, apresentamos apenas algumas manifestações teóricas de alta relevância estética do pensamento ionesquiano que em nosso entendimento têm valor universal em defesa da liberdade e do humanismo.

\section{NOTA}

${ }^{1}$ Professor Associado da Universidade Estadual do Rio de Janeiro - UERJ. Presidente da Academia Brasileira de Filosofia. Docteur d'État (Doutor de Estado) em Filosofia - Letras e Ciências Humanas pela Université de Paris I - Panthéon - Sorbonne. Foi orientando de Olivier Revault d'Allones, e estudou com Jean-François Lyotard, Jacques Rancière e François Châtelet em Paris. Cavaleiro da Ordem das Palmas Acadêmicas, República da França. Doutor Honoris Causa pela Universidade Soka, Tóquio, Japão. 


\section{REFERÊNCIAS}

BONNEFOY, Claude. Entretiens avec Eugène Ionesco. Paris: Ed. Pierre Belfond, 1966.

IONESCO, Eugène. Journal en miettes. Paris: Ed. Gallimard, 2007.

IONESCO, Eugène. Un homme en question. Paris: Ed. Gallimard, 1979.

IONESCO, Eugène. Antidotes. Paris: Ed. Gallimard, 1977.

IONESCO, Eugène. Notes et contre-notes. Paris: Ed. Gallimard, 1966. 